\title{
Title: A call for action to combat the growing synthetic opioid epidemic: The need for the creation and expansion of addiction and psychiatric nursing programs
}

\author{
Ehsan Jozaghi, BA, MA, PhD ${ }^{\mathbf{1 , 2}}$ and Zahra Dadakhah-Chimeh, BSc ${ }^{3}$ \\ Pre-publication version 2017 \\ Published in \\ The Journal of School Nursing, 34(1), 11-13.
}

To link to this article: $\underline{\text { https://doi.org/10.1177/1059840517746729 }}$

1 The British Columbia Centre for Disease Control, Vancouver, British Columbia, Canada

2 The School of Population and Public Health, Faculty of Medicine, University of British Columbia, Vancouver, British Columbia, Canada

${ }^{3}$ The Psychiatrist Nursing Program, Faculty of Health Sciences, Douglas College, Coquitlam, British Columbia, Canada

\begin{abstract}
Authors' note:
The views expressed by Ehsan Jozaghi and Zahra Dadakhah-Chimeh in this letter are those of the authors, and they may not necessarily express the views of the Canadian Institutes of Health Research (CIHR), Ottawa, Ontario, the British Columbia Centre for Disease Control (BCCDC), Vancouver, British Columbia or Douglas College, Coquitlam, British Columbia. In addition, the ClHR, the BCCDC, and Douglas College had no influence on the scope, design, writing, or the direction of this letter.
\end{abstract}

\section{Acknowledgment:}

We would like to thank Caimen Yen for the editorial assistance on this letter. In addition, thanks to anonymous reviewers who improved the earlier versions of this letter.

\section{Funding}

The author(s) disclosed receipt of the following financial support for the research, authorship, and/or publication of this article: The contribution by Ehsan Jozaghi was supported by the Canadian Institutes of Health Research (CIHR) Postdoctoral Fellowship (201511MFE-358449-223266).

\section{Author biographies}

Ehsan Jozaghi is a postdoctoral research fellow at University of British Columbia in Vancouver, Canada. Ehsan has worked closely with people who have had lived experiences of illegal drug use in the past and his research is reflective of this close collaborations. His primary research and work revolves around improving the health care delivery to marginalized populations through evaluation and research.

Zahra Dadakhah-Chimeh has a bachelor of science in medical lab technology. She is currently enrolled in the bachelor of health sciences in psychiatric nursing at Douglas College in Coquitlam, British Columbia, Canada. Zahra has previously served as a community member at Simon Fraser University's research ethics board. Zahra's research interests are youth, trauma, and substance abuse. 


\section{A call for action to combat the growing synthetic opioid epidemic: The need for the creation and expansion of addiction and psychiatric nursing programs}

Dear Editor,

\section{Background}

In today's society, the number of fatal overdose cases attributed to opioids and synthetic opioids has surpassed the frequency of motor vehicle accidents in many jurisdictions (Hadland, Wood, \& Levy, 2016). For example, 50,000 Americans (a population of an average town in North America) have lost their lives due to unintentional opioid overdose fatalities (Rudd, 2016). While many researchers and policy makers have offered suggestions that address some of the root causes of the current epidemic, such as excessive prescription practices by physicians (Compton, Jones, \& Baldwin, 2016), economic uncertainties (Monnat, 2016), heroin oversupply, and the introduction of synthetic opioids in the illegal markets (Ciccarone, 2017), little attention has been given to the role of evidencebased health care - more specifically, the role of nurses in managing and containing the epidemic. In fact, there is growing evidence of the negative attitudes directed toward people with substance use and mental health disorders by nurses and health-care professionals due to their lack of knowledge and hands-on training/experience which in turn diminishes a patient's access to adequate health care (Hamilton et al., 2014; The National Center on Addiction and Substance Abuse at Columbia University, 2012; van Boekel, Brouwers, Van Weeghel, \& Garretsen, 2013).

\section{Ways Forward}

Global substance use and mental health disorders continue to impact our communities both financially and emotionally, with over a 37\% increase in the burden of cases between 1990 and 2010 (Whiteford et al., 2013). While more recent epidemics — such as HIV/AIDs, Avian Flu, Swine Flu, Ebola, and Zika outbreaks-have received the greatest media attention and financial contributions from health and government agencies, substance use and mental health disorders have been neglected, and health-care resources have failed to commensurate with the burden (Whiteford et al., 2013). Moreover, the shortage of skilled and knowledgeable health-care professionals who have received evidence-based training and experience with the unique needs of people with addiction and mental health disorders may hinder patients in seeking and succeeding with their specialized health care, diagnosis, or treatment (McCutcheon \& Morrison, 2014).

This is particularly true, as previous research has shown high prevalence of problematic drug, alcohol use, and high risk of opioid injection drug use initiation in pediatric patients (Cerda', Santaella, Marshall, Kim, \& Martins, 2015; Knight et al., 2007). Recent advancements in the fields of addiction nursing and harm reduction practices have the potential to offer new avenues to target marginalized patients (Bowman, Eiserman, Beletsky, Stancliff, \& Bruce, 2013). For example, innovations in nursing strategies and interventions targeting people with substance use disorders play an essential role in the screening and treatment of vulnerable patients (Voon, Johnson, Small, Wood, \& Klimas, 2017).

\section{Next Steps}

With some researchers predicting that synthetic opioids will become recurrent, permanent, or the "new norm" in the illegal markets, there is an urgent need to tackle this crisis through a health-care-based and evidence-based model of harm reduction, treatment, and prevention. There have been several evidenced-based harm reduction recommendations at the state level that highlight access to primary care as an ethical and human rights issue, the implementation of supervised consumption/injection facilities, free naloxone distribution, opioid agonist substitution treatments, and supportive housing (Thomson, Lampkin, Maynard, Karamouzian, \& Jozaghi, 2017). There is still, however, a public health approach needed to address the complexities of the current synthetic opioid crises. This is particularly relevant, as previous researchers have raised the alarm regarding skill deficits in the public health workforce, specifically an overreliance on experience and on-the-job trial and error as well as enhanced accreditation of public health workers (Kaufman et al., 2014; U.S. Department of Health and Human 


\section{Letter to editor}

Services, 2016). The ability to properly equip our health-care system with knowledgeable nurses, public health officials, and health-care providers who are trained in and acquainted with mental health and substance use disorders is one solution that addresses the needs of our current vulnerable, at-risk, and marginalized patients. Specifically, there should be greater emphasis placed on nursing programs and school health services that are tailored toward atrisk and vulnerable adolescents. For example, a recent article indicates that individuals who are placed in child welfare systems, entrenched in illegal substance use, living with blood-borne infections, female and children of Indigenous ancestry are more likely to die of an overdose case, even prior to the recent introduction of potent forms of synthetic opioids in the illegal markets (Jongbloed et al., 2017). For Indigenous children and youth, it is estimated that they are 13 times more likely to die of overdose events when compared to the general population (Jongbloed et al., 2017). Currently in North America, the British Columbia Centre on Substance Use (2017) is the only program to offer addiction nursing fellowships to four registered nurses per year. Therefore, through the expansion of new programs for registered nurses providing enhanced addiction education programs for nurses already employed in the field - especially nurses who work in schools - in addition to increasing public awareness in schools about addiction as a physiological disease, we will see improvements in the capability and capacity of our health-care system, which in turn will initiate the possibility to overcome the synthetic opioid crisis by preventing and diminishing future costs of substance abuse and mental health cases in our communities. 


\section{Letter to editor}

\section{References}

British Columbia Centre on Substance Use. (2017). The addiction nursing fellowship program. Retrieved from https://www.bccsu.ca/addiction-medicine-clinical-research-fellowship-overview/addiction-nursing-fellowship/

Bowman, S., Eiserman, J., Beletsky, L., Stancliff, S., \& Bruce, R. D. (2013). Reducing the health consequences of opioid addiction in primary care. The American Journal of Medicine, 126, 565-571.

Cerda', M., Santaella, J., Marshall, B. D., Kim, J. H., \& Martins, S.S. (2015). Nonmedical prescription opioid use in childhood and early adolescence predicts transitions to heroin use in young adulthood: A national study. The Journal of Pediatrics, 167,605-612.

Ciccarone, D. (2017). Fentanyl in the US heroin supply: A rapidly changing risk environment. The International Journal of Drug Policy, 46, 107-111.

Compton, W. M., Jones, C. M., \& Baldwin, G. T. (2016). Relationship between nonmedical prescription-opioid use and heroin use. The New England Journal of Medicine, 374, 154-163.

Hadland, S. E., Wood, E., \& Levy, S. (2016). How the paediatric workforce can address the opioid crisis. The Lancet, 388, 1260.

Hamilton, S., Lewis-Holmes, E., Pinfold, V., Henderson, C., Rose, D., \& Thornicroft, G. (2014). Discrimination against people with a mental health diagnosis: Qualitative analysis of reported experiences. Journal of Mental Health, 23, 88-93.

Jongbloed, K., Pearce, M. E., Pooyak, S., Zamar, D., Thomas, V., Demerais, L., . . Yoshida, E. M. (2017). The Cedar Project: Mortality among young Indigenous people who use drugs in British Columbia. Canadian Medical Association Journal, 189, E1352-E1359.

Kaufman, N. J., Castrucci, B. C., Pearsol, J., Leider, J. P., Sellers, K., Kaufman, I. R., . . Sprague, J. B. (2014). Thinking beyond the silos: Emerging priorities in workforce development for state and local government public health agencies. Journal of Public Health Management and Practice, 20, 557.

Knight, J. R., Harris, S. K., Sherritt, L., Van Hook, S., Lawrence, N., Brooks, T., . .Kulig, J. (2007). Prevalence of positive substance abuse screen results among adolescent primary care patients. Archives of Pediatrics \& Adolescent Medicine, 161, 1035-1041.

McCutcheon, J. M., \& Morrison, M. A. (2014). Injecting on the Island: A qualitative exploration of the service needs of persons who inject drugs in Prince Edward Island, Canada. Harm Reduction Journal, 11, 1-11.

Monnat, S. M. (2016). Deaths of despair and support for Trump in the 2016 presidential election. Department of Agricultural Economics Research Brief, Pennsylvania State University. Syracuse, NY. Retrieved from: http://aese.psu.edu/directory/smm67/Election16.pdf

Rudd, R. A. (2017). Increases in drug and opioid-involved overdose deaths-United States, 2010-2015. Morbidity and Mortality Weekly Report, 66, 35-35.

The National Center on Addiction and Substance Abuse at Columbia University. (2012). Addiction medicine: Closing the gap between science and practice. New York, NY: CASA Columbia. Retrieved from file:///C:/Users/Owner/Downloads/Addiction-medicine-closing-the-gap-between-science-and-practice.pdf

Thomson, E., Lampkin, H., Maynard, R., Karamouzian, M., \& Jozaghi, E. (2017). The lessons learned from the fentanyl overdose crises in British Columbia, Canada. Addiction, 112, 2068-2070. 


\section{Letter to editor}

U.S. Department of Health and Human Services. (2016). Public Health 3.0: A call to action to create a 21st century public health infrastructure. Retrieved from https://www.healthypeople.gov/sites/default/files/Public-Health-3.0-

White-Paper.pdf

van Boekel, L. C., Brouwers, E. P., Van Weeghel, J., \& Garretsen,H. F. (2013). Stigma among health professionals towards patients with substance use disorders and its consequences for healthcare delivery: Systematic review. Drug \& Alcohol Depedence, 131, 23-35.

Voon, P., Johnson, C., Small, W., Wood, E., \& Klimas, J. (2017). Nursing fellowship in addiction medicine: A novel program in a Canadian setting. Journal of Addictions Nursing, 28, 148-149.

Whiteford, H. A., Degenhardt, L., Rehm, J., Baxter, A. J., Ferrari, A. J., Erskine, H. E., . . Burstein, R. (2013). Global burden of disease attributable to mental and substance use disorders: Findings from the Global Burden of Disease Study 2010. The Lancet, 382, 1575-1586. 